Supplement of Hydrol. Earth Syst. Sci., 19, 3449-3456, 2015

http://www.hydrol-earth-syst-sci.net/19/3449/2015/

doi:10.5194/hess-19-3449-2015-supplement

(C) Author(s) 2015. CC Attribution 3.0 License.

(c) (1)

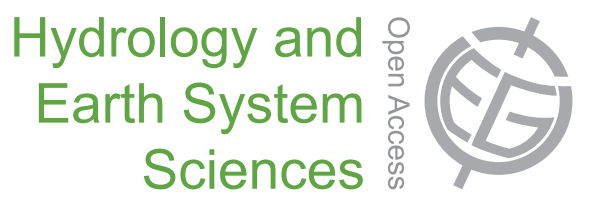

Supplement of

\title{
The representation of location by a regional climate model in complex terrain
}

\author{
D. Maraun and M. Widmann \\ Correspondence to: D. Maraun (dmaraun@geomar.de)
}

The copyright of individual parts of the supplement might differ from the CC-BY 3.0 licence. 

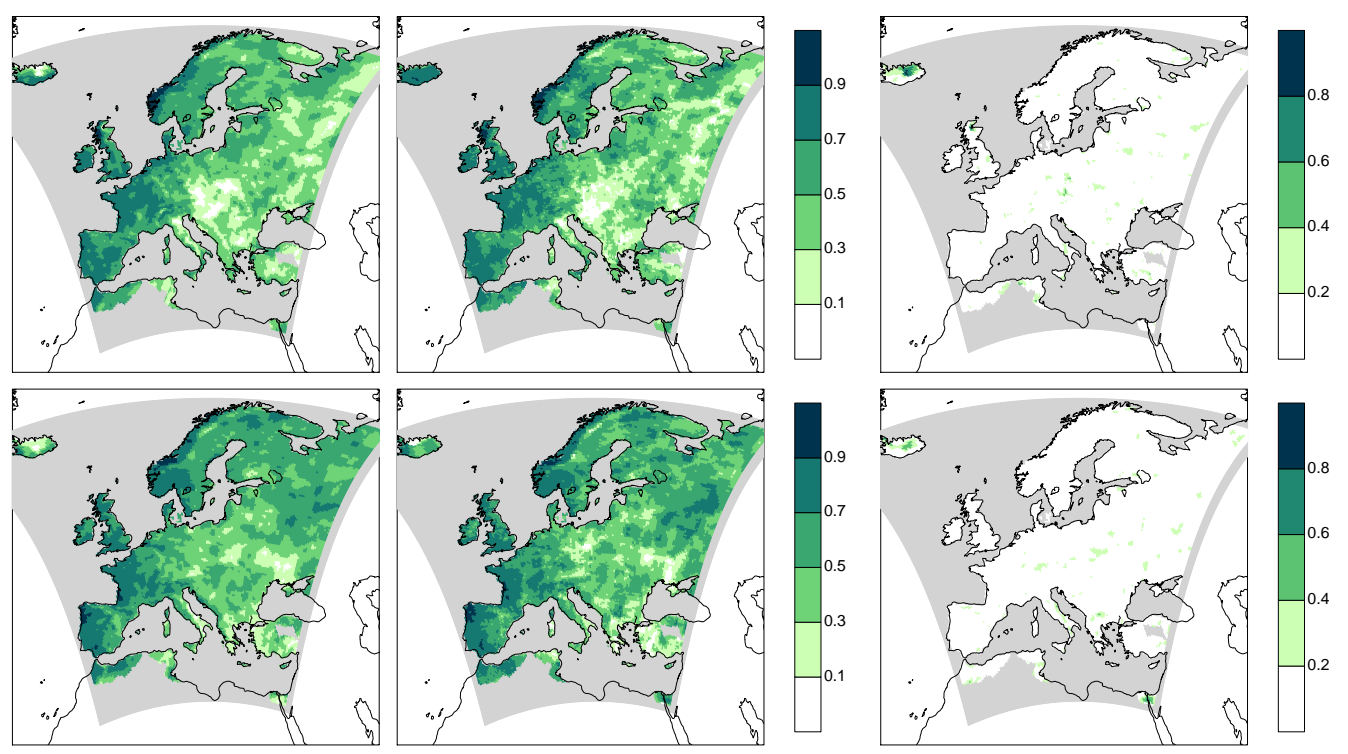

Figure S1: Location representativeness. Left: local representativeness, i.e., correlation betweenlocal (at the same grid box) simulated and observed seasonal mean time series.

Center: non-local representativeness, i.e., correlation between observed seasonal mean time series and modelled time series at non-local grid box that maximizes correlation with observations. Right: improvement in correlation by using non-local series. Top: MAM; bottom: SON.
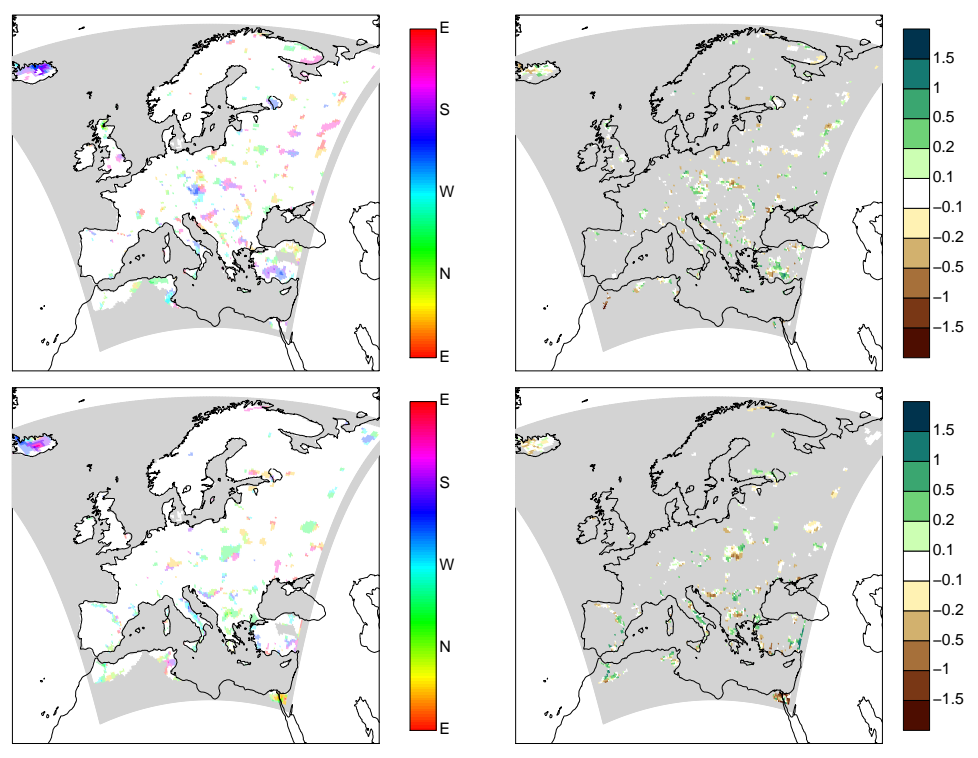

Figure S2: Left: direction of model grid box that maximizes correlation relative to local gridbox. Right: reduction in absolute trend bias by non-local approach; trends measured in percent per decade. Green: bias reduced; brown: bias increased. Areas where correlation does not improve by at least 0.2 are shown in white/grey. Top: MAM; bottom: SON. 